\title{
Sinicisation and ethnicity: spatial characteristics of Shui vernacular architecture in Guizhou, Southwest China
}

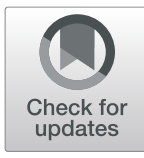

Yizhi Zhou ${ }^{1 *}$ and Miao Wei ${ }^{2}$

\begin{abstract}
The Shui people are an ethnic minority living in southern mountainous areas of Guizhou Province, China; they have retained many vernacular houses with a history of over a century. Using spatial analysis software depthmapX to perform visibility graph analysis and field-of-view analysis with space syntax, we examined the sequence, organisation, and hierarchy of the living space in Shui residences. We found that those residences were influenced by external cultures, resulting in two types of plan layout: front-middle-back (type A) and left-middle-right (type B). Those two types of spatial combination were evident in two different line-of-sight axes. With type $A$, the hearth was the core and served as the daily living space of the family. With type B, the ancestral altar was the core and served as the ritual space. The historical coexistence and changing relationship of the two axes reflect cultural exchange between the Shui and Han as well as with other foreign cultures. This study concludes that the diversity of spatial forms that developed in different historical periods is an important attribute of Shui houses and those of other ethnic minorities in Southwest China.
\end{abstract}

Keywords: Vernacular architecture, Shui ethnic group, Spatial analysis, Sinicisation, Ethnicity, Cultural exchange

\section{Introduction}

Among the world's ethnic minority areas, indigenous cultural traditions coexist with the influence of the dominant culture; their interrelationship has changed throughout history. That dynamic process has shaped the often-underestimated diversity of the built heritage in such areas. In studies about the built heritage in China's ethnic minority areas, there are two major problems. One is that most research tends to interpret such minority architecture as stable and ahistorical. Studies have largely ignored the dynamic, changing process in different historical periods; that is particularly the case with respect to the twentieth century, when rural areas of China underwent radical economic and social transformation (Xu et al. 2011; Long and Liu 2016). The

\footnotetext{
* Correspondence: zhouyizhihistory@hotmail.com

${ }^{1}$ College of Architecture and Urban Planning, Tongji University, 1239 Siping

Road, Yangpu District, Shanghai 200092, China

Full list of author information is available at the end of the article
}

other problem is that most research tends to focus on 'indigenous culture' (yuanshengtai); it ignores potential cultural exchanges in ethnic minority areas in the premodern and modern periods (Bao 2015). Such problems have led to the widely questioned issue of how to define the value of 'authenticity' in preserving and regenerating today's built heritage (Zhang et al. 2006; Wu 2014).

Guizhou Province in Southwest China is an area with many ethnic minorities, who live in the high mountains. Among them are the Shui (who call themselves Sui). Thanks to their cultural advantages (own written language), stable settlements, few historical conflicts with the central government, and large number of preserved vernacular houses from different periods, the Shui are ideal for studying complex cultural exchange in Southwest China over recent centuries.

Shui houses resemble those of other ethnic minorities in southern Guizhou. Steep mountains are a feature of that region. Thus, the vernacular houses usually have a

\section{Springer Open}

(c) The Author(s). 2021 Open Access This article is licensed under a Creative Commons Attribution 4.0 International License, which permits use, sharing, adaptation, distribution and reproduction in any medium or format, as long as you give appropriate credit to the original author(s) and the source, provide a link to the Creative Commons licence, and indicate if changes were made. The images or other third party material in this article are included in the article's Creative Commons licence, unless indicated otherwise in a credit line to the material. If material is not included in the article's Creative Commons licence and your intended use is not permitted by statutory regulation or exceeds the permitted use, you will need to obtain permission directly from the copyright holder. To view a copy of this licence, visit http://creativecommons.org/licenses/by/4.0/. 
stilt structure with elevated floors: the ground floor is for raising livestock, and the upper floors are living spaces. There are two main structural types of such stilt houses. One is called ganlan; it is an older stilt type of dwelling and has an entirely raised living floor (Fig. 1, left). The other is called diaojiaolou; it has a partially elevated living floor and is found only on mountain slopes (Fig. 1, right). The raised living floor often takes the form of 'one bright, two dark': an ancestral hall in the central bay (bright) and two rooms on either side (dark). A fire pit (or hearth) is typically located in the central bay.

The spatial arrangement of the living floor distinguishes Shui houses from other southern Guizhou vernacular houses. The living floor features a large public area in the centre, which is a kind of 'open living room', with the hearth and ancestral altar. The location of the hearth and ancestral altar as well as the spatial relationship between the open living room and remaining architectural elements are key features of Shui houses; they deserve further investigation. Hitherto, however, there has been very limited academic interest in Shui residences, probably owing to their seeming lack of distinctive physical features (Yang 2018; Wei 2009; Luo and Li 2016; Lu 2004; Wang 1998). In-depth descriptions and a comprehensive analysis of the notable open living room are particularly lacking; current field survey results do not support a scientific, systematic study in this regard. Thus, new methods need to be adopted in field investigations and data analysis of Shui houses.

\section{Methodology}

In China, the ways that residents use their living space has changed with the country's rapid socioeconomic development. Constant changes to people's traditional practices have also largely blurred their memories of traditional lifestyles, which has led to difficulties in obtaining information through fieldwork and interviews. Space syntax may be applied to examine how people use their living spaces. Many studies have employed space syntax in their spatial analyses of residential buildings (Choi et al. 2014; Ostwald and Dawes 2013), particularly of traditional Chinese houses (Huang et al. 2019). The present study utilised spatial analysis software (depthmapX, UCL) to perform visibility graph analysis and field-of-view analysis with space syntax. Visibility graph analysis allows the superposition of a person's visual range at any position on a plane to identify differences in visibility; it can be used to determine complex behavioral patterns in study subjects. Field-of-view analysis allows the mapping of the visual range from a particular point. This analysis model is based on the reflection of light; it determines peoples' motional behavioral patterns in their environment (Alitajer and Nojoumi 2016).

In this paper, we applied space syntax as the basis for our mapping and sociological fieldwork. We applied the concepts of 'depth' and 'visibility' to quantify and visualise the hierarchical structure of traditional Shui houses toward analysing their spatial composition. Here, 'depth' refers to differences in the distance between the main entrance and the rest of the house owing to different layout plans; 'visibility' refers to the degree of connection between each point in space and other points. Geometrically, this represents the sum of the line segments that can be connected between any point in the gridded plan and other statistical points. Thus, the type of room arrangement and position of the entrance have a great impact on the layout. Employing space syntax to quantify visibility can accurately identify subtle differences in the house layout, which is conducive to typological research. The use of spatial analysis to quantify the spatial organization of traditional houses can lead to robust conclusions; it also helps identify spatial characteristics that would be difficult to discern using conventional research methods.

Most of the Shui live in Sandu County; others reside in Libo, Dushan, Danzhai, and Leishan counties. This paper focuses on the four villages of Bamao (in Sandu), Zenlei (in Sandu), Hongni (in Dushan), and Shuipa (in Libo). We also included three other villages in this study: Sandong (in Sandu), Shuili (in Libo), and Shuifu (in Libo) (Fig. 2).

The selected houses were presumably built between 1900 and the 1970s. The 1950s is usually considered an important turning point in the history of China: radical socialisation changed the concept of the family and also affected housing forms. According to our field study,
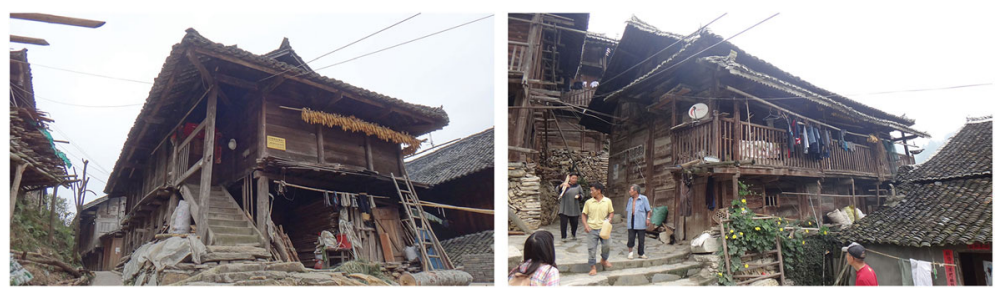

Fig. 1 General appearance of Shui houses: left, house in Zenlei Village; right, house in Bamao Village (Source: the authors) 


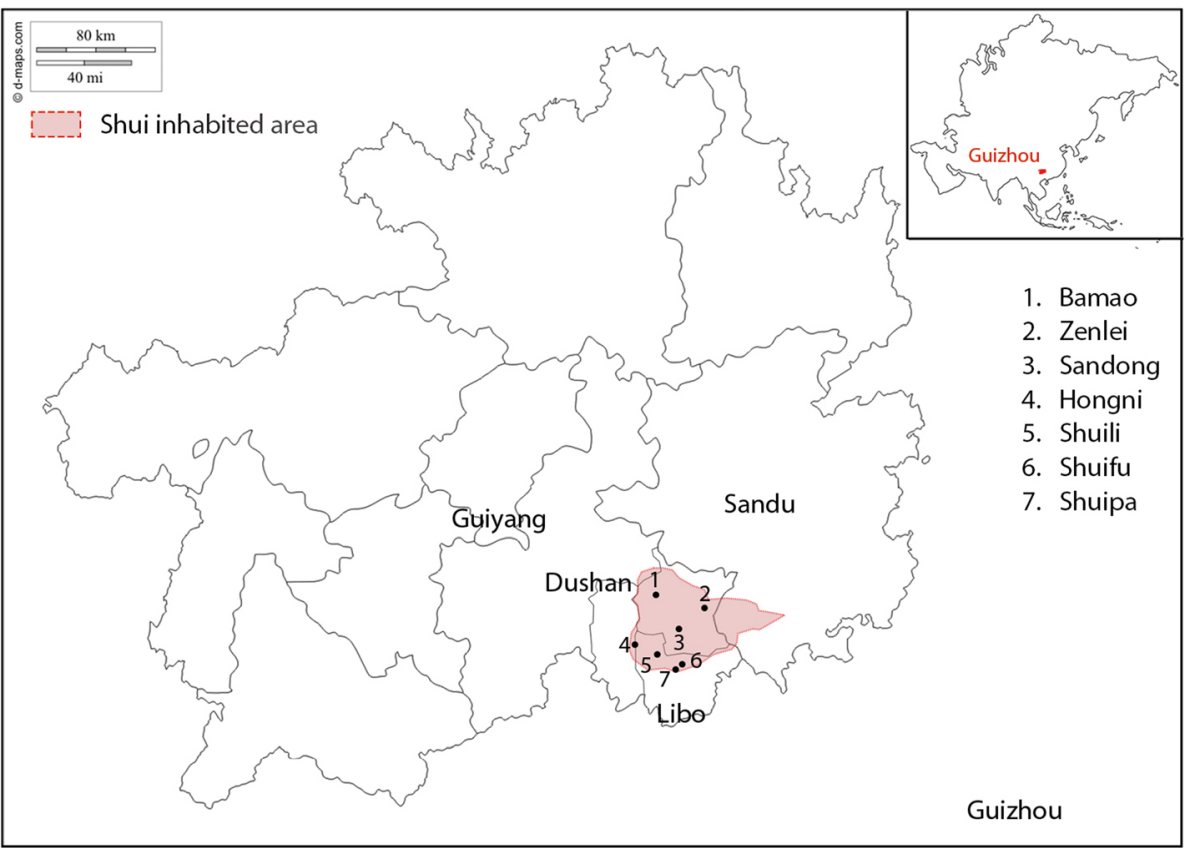

Fig. 2 Map of the area inhabited by the Shui and the case study locations (Source: base map from d-maps.com, drawn by the authors)

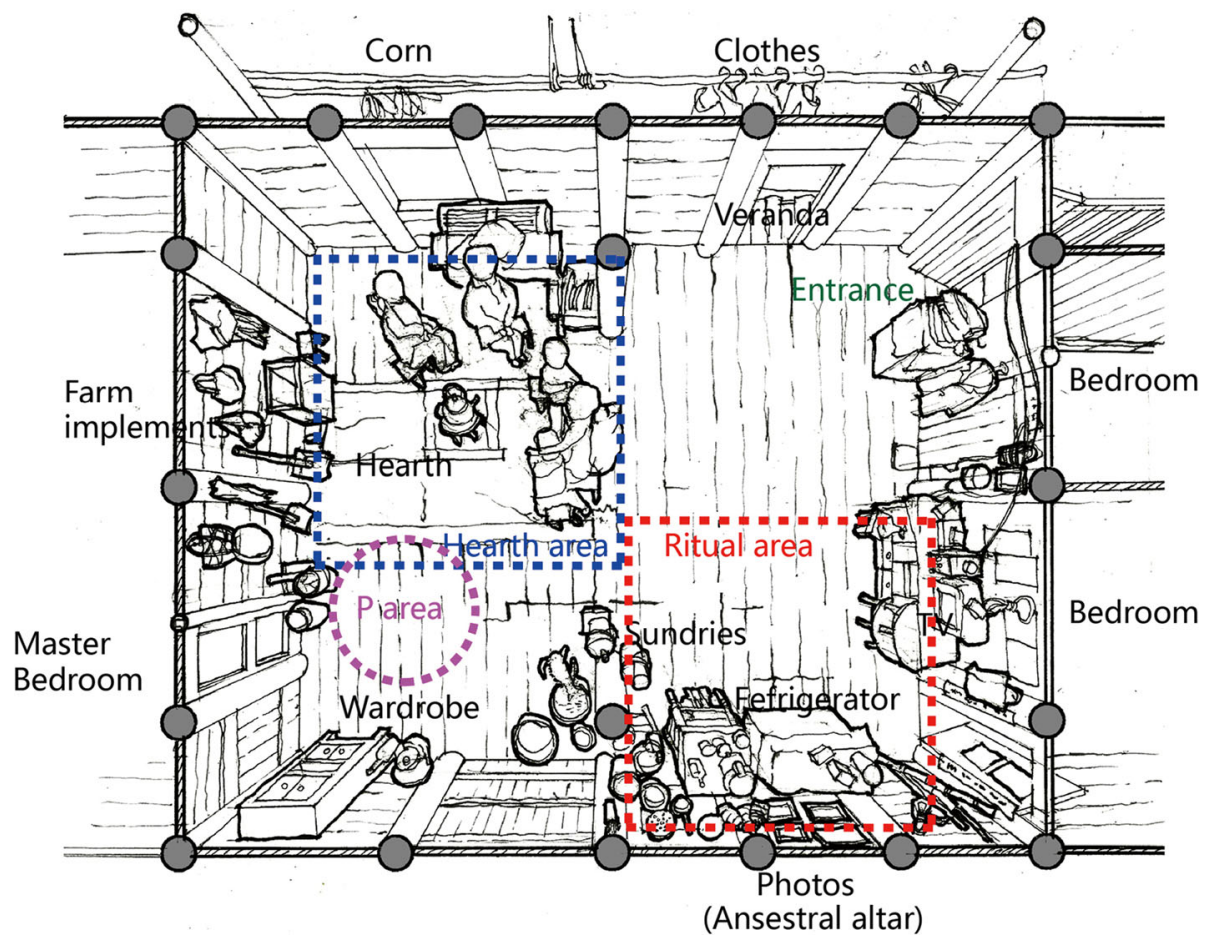

Fig. 3 Wei's open living room in Zenlei Village (Source: the authors) 
most 'new houses' built between the 1950s and 1970s still used a traditional timber structure and presented clear traditional characteristics. From the 1980s to 2010s, a large number of timber dwellings could still be observed in Guizhou minority areas; however, by then, the differences between Shui houses and those of other minorities or even the Han were very small. Thus, Shui wooden houses built in that period are not considered in this paper.

\section{Spatial arrangement of Shui vernacular houses}

In a Shui house, the space of the living floor can be divided into private and public areas. Private areas include the bedrooms, storage rooms, and children's rooms. The functions of the private areas may often change; however, as the name indicates, they are always used for private purposes. Public areas mainly include the open living room and veranda. The open living room and the position relationship of the various spatial elements in that room are the main focus of this paper. In Shui culture, cardinal direction is not a vital consideration; thus, we considered only the relative relationship with respect to orientation in the open living room. Regarding the orientation relationship, we addressed the relative positional relationship of the indoor space with respect to the main entrance of the house.

\section{Two major spatial elements in the open living room}

Among the minority groups in Southwest China, the open living room, where most family events take place, is the most distinctive feature of a Shui house. That room is divided into two parts: the ritual area and the hearth area. The former is for ancestor worship rites; the latter is the daily living space. Nowadays, most Shui spend their time beside the hearth in winter and move to the ritual area in other seasons (Fig. 3).

The ritual area, which is called the degan in the Shui language, is a place for ancestral worship; its spatial arrangement is similar to that with ritual areas of the Han. The degan usually occupies one corner of the open living room. As the main focus of that room, the degan basically consists of an altar and a shrine; the worship area is located in front of them. Today, the ritual area is gradually becoming an increasingly secular space for daily use. Modern household items, such as refrigerators, televisions, cabinets, and other home appliances, encroach on the ritual area. Interestingly, expensive domestic appliances are found in the ritual area, which shows the greater importance accorded to that space among the Shui (Fig. 4).

The hearth, which is called the geha or gaha in the Shui language, is a spatial element that is uncommon in Han areas. It functions as the major reception area, and the Shui regard it as a symbol of a family. When Shui families invite guests to visit their homes, they usually first ask, 'Would you please come to see my hearth?' (Wei 2009). The traditional hearth formerly served as a place for cooking and heating; now, however, cooking is done with a Han-style hearth (zao) on the ground floor. Thus, the Shui use their traditional hearth only to keep warm in winter (Fig. 3).

The open living room of a Shui house has no fixed furniture except in the ritual and hearth areas, which may be used for work (making textiles and handicrafts) and also for receiving visitors. We observed that there was a special area in front of one bedroom that was particularly used to receive important visitors. That bedroom was normally used by elderly family members, but it did not appear to have a special name. Therefore, in this paper, we use the term 'master bedroom' to refer to that special room; we call the special area in the open living room in front of the master bedroom the $\mathrm{P}$ area.

\section{Sequence of spatial elements: types A and B}

It is widely accepted that with ethnic minority housing in Southwest China, the hearth is an inherent space and has ancient cultural origins; the ancestral hall is the result of the Han culture's ancestor worship ceremony. The combination of the hearth and ritual areas is a key feature of Shui houses. By applying the concept of depth in space syntax, it is possible to determine the hierarchy of the spatial elements by analysing the relationship between such elements and the main entrance. The spatial sequence can then be clarified. By applying this approach, we observed two different spatial sequences in Shui houses.
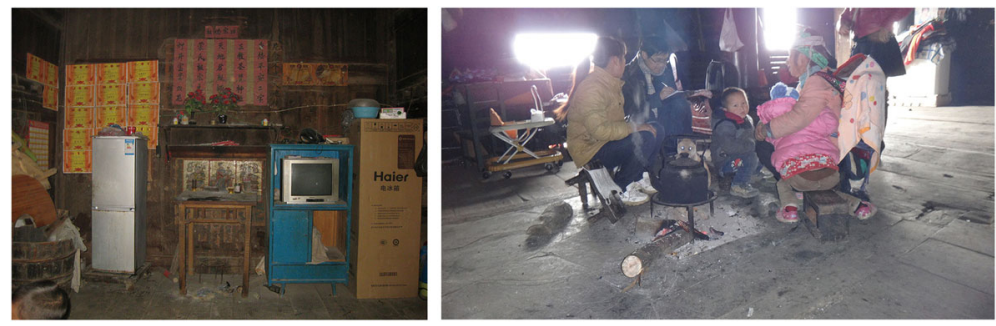

Fig. 4 Ancestral altar (left) and traditional hearth (right) in Shui houses (Source: the authors) 
Type A

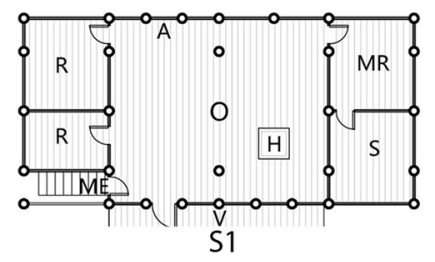

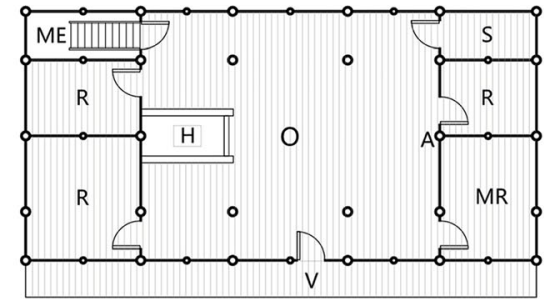

S2 (by Luo, D. 2016)

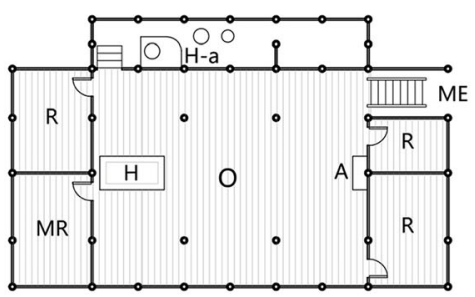

S3 (by Lu, Y. 2004)

Transitional Form
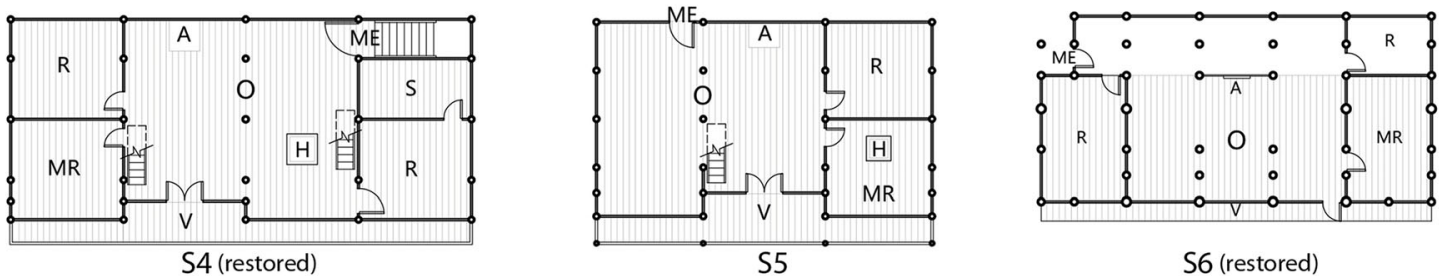

Type B

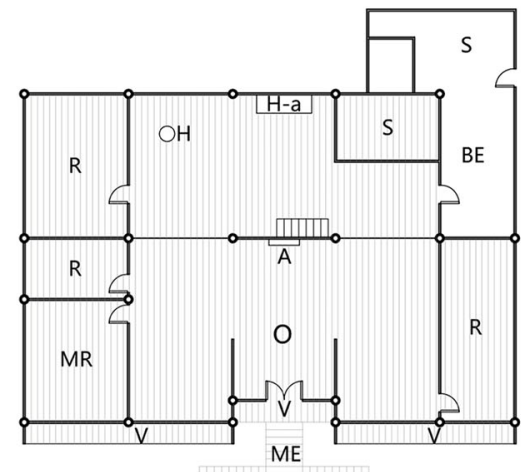

S7 (by Yang, T. 2018)

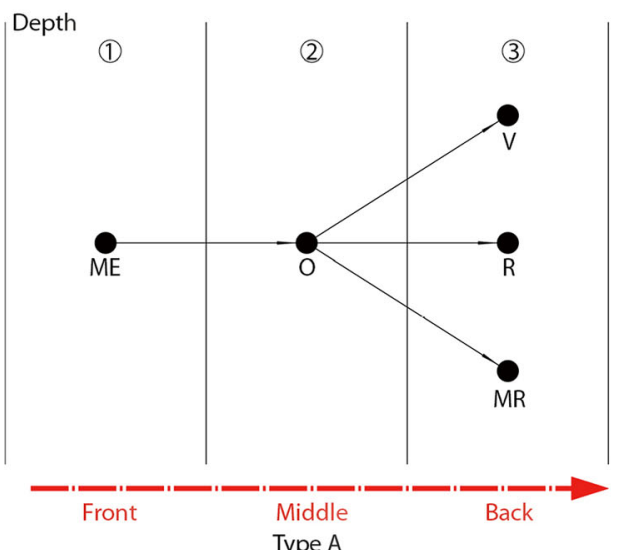

\begin{tabular}{|c|l|}
\hline O & Open living room \\
\hline A & Altar \\
\hline ME & Main entrance \\
\hline RE & Rare entrance \\
\hline H & Hearth \\
\hline H-a & Han-style hearth \\
\hline MR & Master room \\
\hline R & Room \\
\hline S & Storage \\
\hline V & Veranda or porch \\
\hline
\end{tabular}

S8 (by Yang, T. 2018)

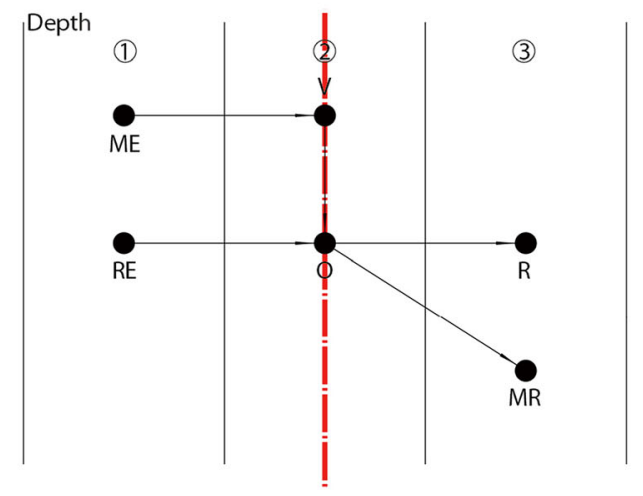

axis of symmetry

Type B

Fig. 5 With eight typical floor plans of Shui houses (from fieldwork and the literature), we analysed the spatial relationship of the two main types, which we evaluated from the spatial depth of their topological relationship. We found that the type-A floor plan had a tree structure with a 'front-middle-back' layout; the type-B floor plan had a symmetrical 'left-middle-right' layout (S2, source: Luo and Li 2016; S3, source: Lu 2004; S7 and S8, source: Yang 2018; others, source: the authors) 
According to the connection between the core public area and other spaces in the house, we could categorise the living floor of Shui houses into two types. With type A, the open living room is the core public area; all other spaces (expect for storage) directly connect with it. This gives the type-A floor plan a tree structure with a 'frontmiddle-back' layout. With type B, the core public area combines the veranda and open living room; when an entrance stairway is added to the front veranda, the veranda and open living room have equal depth. Rooms are symmetrically arranged around the veranda and open living room with type B, giving this type a 'leftmiddle-right' layout (Fig. 5).

With the four cases investigated in our field studies between 2013 and 2014 and four cases cited in the literature, we found the following: three cases were typical type A; two cases were typical type B; and the other three cases showed a transitional character. The construction time of
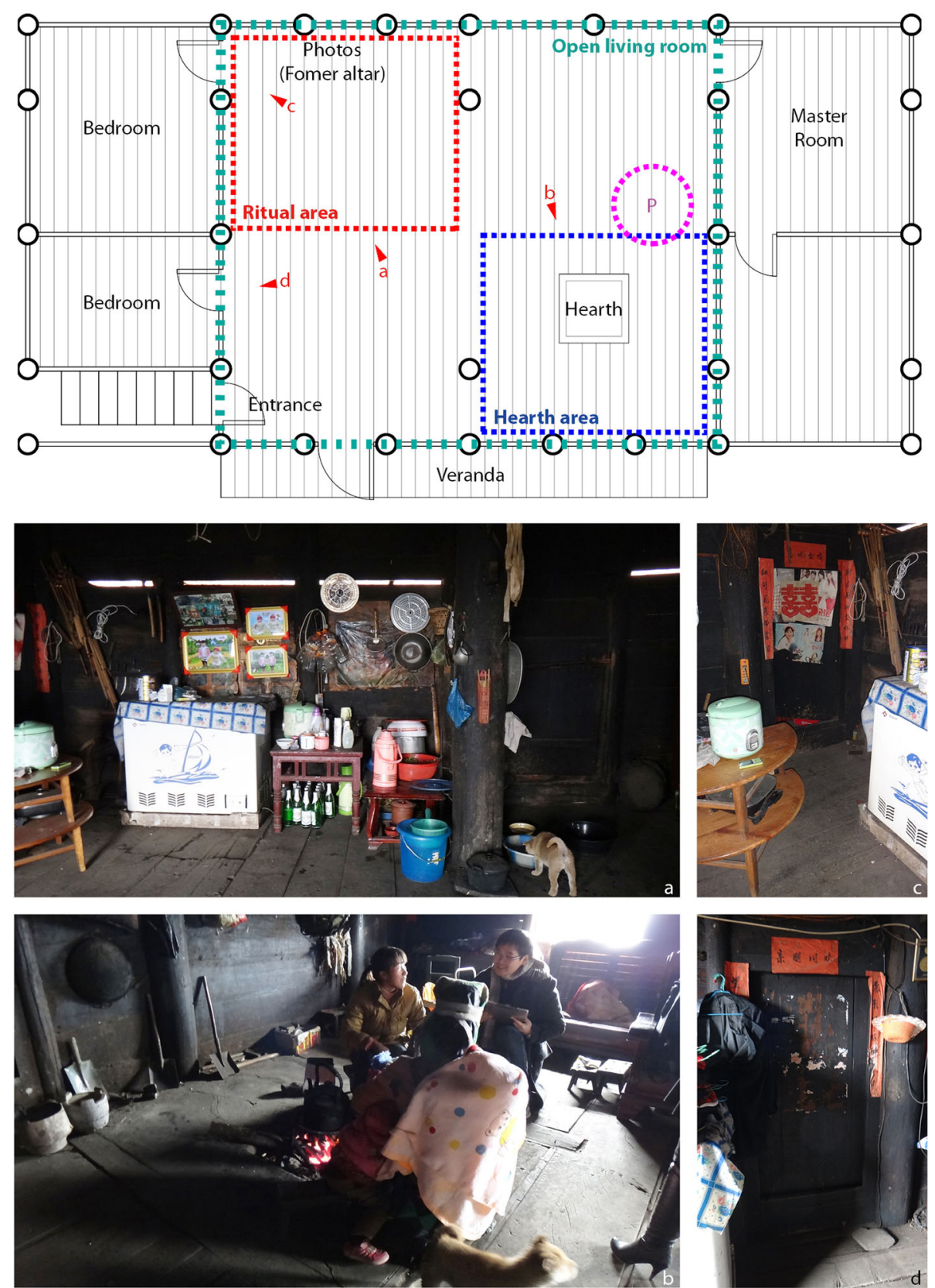

Fig. 6 Floor plan and photos of S1 show the typical type-A layout; the open living room had a ritual area (photo a), hearth area, and P area (photo b). P area is on the way to the master room while the entrance to the other rooms are narrow and blocked with furnishers (photo $\mathrm{c}$ and d) (Source: the authors) 
type A was generally earlier than with type B. Primarily, type B was not built earlier than the 1960s, indicating the change in the layout of Shui houses.

The first case of type A was Gangheng Wei's house (S1) in Zenlei Village, Sandu County; this registered heritage building was built in the late Qing Dynasty (late nineteenth century). The stilt house had four bays with a gable-and-hip roof. Surrounded by three rooms, the open living room occupied the two bays in the middle of the main living floor. The hearth was located on the front-right side in front of the main entrance; a television, refrigerator, cabinets, and tables for daily living occupied the opposite corner on the rear-left side. In front of the open living room, there was an overhanging veranda without a handrail; it was used to hang clothes and dry grain.

S1 had a typical type-A plan. The former ancestral altar space was located on the opposite corner of the hearth. However, no ancestral altar was present: photos of the family's children hung on the wall, indicating the spatial properties of an altar. Most of the family's sundry items were stacked on the front-left side near the main entrance; visitors were received around the hearth in front of the master bedroom (P area) (Fig. 6).

The second case of type A was another house (S2) in Zenlei Village (Luo and Li 2016). S2 was also a registered cultural heritage building dating from the late nineteenth century; it was a stilt house with five bays
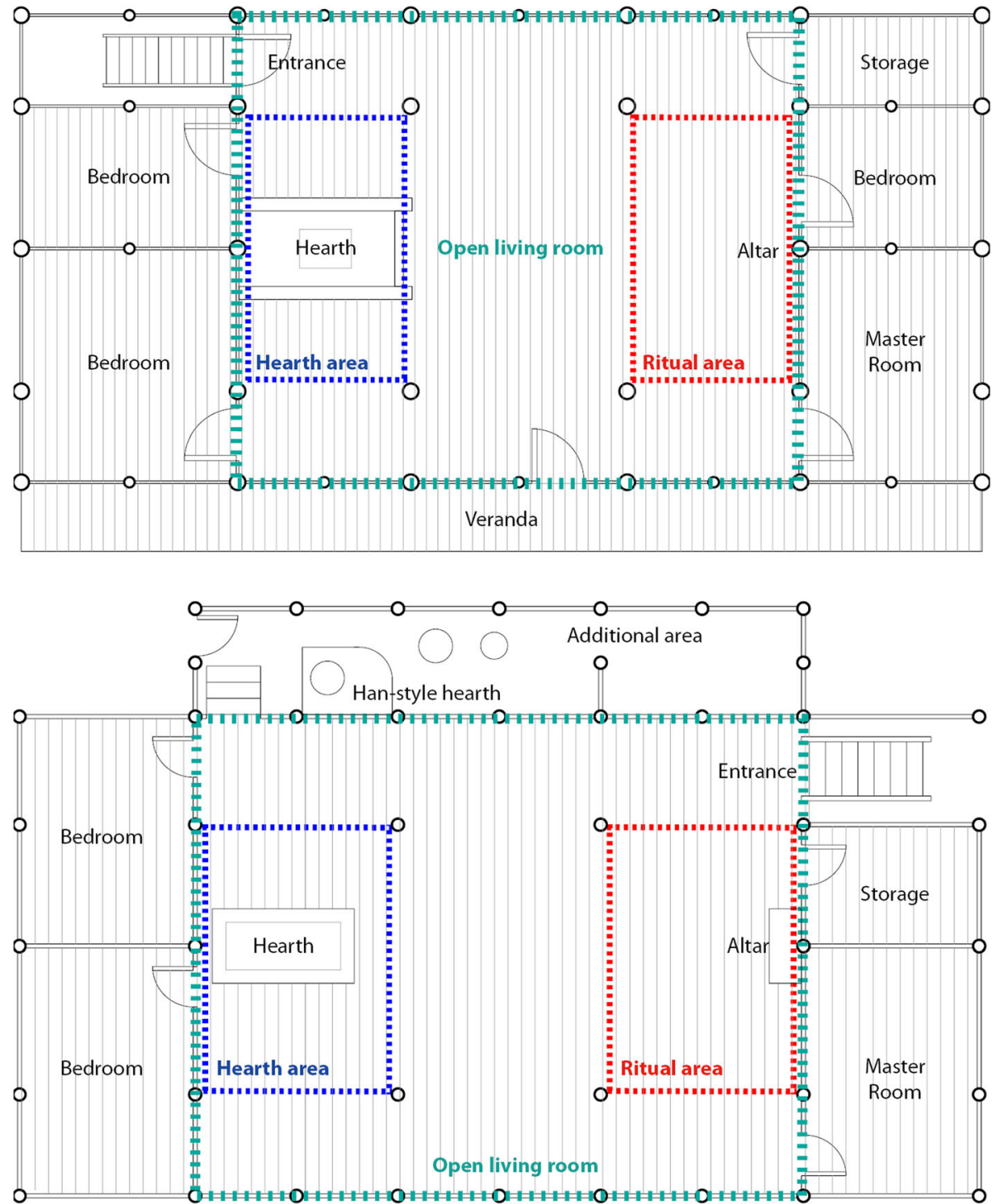

Fig. 7 The floor plans of S2 (upper) (source: Luo and Li 2016) and S3 (lower) (source: Lu 2004) show that the ancestral altar was always opposite the hearth with type A 
and a three-bay open living room. The floor plan was quite different from S1. With S2, the hearth was located on the front-right side near the main entrance of the three-bay open living room; the hearth was not at the corner but along the left side. However, similar to S1, the ancestral altar was opposite the hearth; the master bedroom and $\mathrm{P}$ area in the open living room were on the rear-right side furthest from the main entrance.

The third case of type A was a house (S3) in Sandong Town, Sandu County whose construction time was unknown (Lu 2004). It was another five-bay stilt house with a three-bay open living room. Unlike S2, S3 did not have a front veranda, but it had a kitchen added at the back of the house. The entrance to S3 was located at the right rear of the house instead of at the front. However, the layout of the hearth and ritual area was the same as with S2 (Fig. 7). There was no information about the location of the master bedroom ( $\mathrm{Lu} 2004)$. However, we infer that the hierarchies of the hearth and ancestral altar may have differed between S3 and S2.

Type A houses can be found over all the areas inhabited by the Shui. Usually they were built no later than the 1950s. The spatial sequence of this type presented a tree structure from the entrance (root) to the open living room (trunk) and finally to the veranda, bedrooms, and other spaces (branches). We observed that all the open living rooms with type A were asymmetrical; the spatial hierarchy of the hearth and ancestral altar was equal. An important feature with type A was that there was no main entrance at the front; generally, there was only a small door leading to the outdoor drying platform. Even-numbered structural bays were often used; that is extremely rare in Han houses (Fig. 8).

House A (S7) in Shuipa Village, Libo County (Yang 2018) had a typical type-B layout. It was a stilt house built in the 1970s with five bays, including a three-bay open living room. The most notable feature of S7 was its use of a 'central axis'. Along that axis, there were the main entrance, ritual area, and ancestral altar (located at the geometric centre of the house). The house had two entrances: the main entrance was located along the central axis leading to the altar-very much as in Han houses. The entrance at the rear of the house (used as the only entrance with type A) was employed just as a standby entrance. Subsequently, a bathroom and toilet were added to the standby entrance area (Fig. 9).

The second difference between S7 and type A is the transformation of the spatial organisation of the open living room. According to Yang (2018), the three-bay open living room of S7 was divided into four areas: the area behind the ancestral altar was the kitchen area; that in front of the ancestral table was the ritual area; that to the right of the altar (near the rear entrance) was a workspace; and that to the left of the altar (far from the rear entrance) was for visitors and daily living. It is notable that with S7, the altar was in the centre and created a strong sense of symmetry; however, the typical streamlining with type A (i.e., from the back door through the open living room to the $\mathrm{P}$ area and finally into the master room) was still present.

House B (S8) in Shuipa Village, Libo County (Yang 2018) was the second case of type B. It was built in the 1960s, and it was a five-bay house with a three-bay open living room. The spatial organisation of S8 was basically the same as with S7: the main entrance, ritual area, and ancestral altar were all located along the central axis. With S8, the open living room was also divided into four areas. However, it is noteworthy that the rear entrance of S7 was located to the right of the house, whereas with S8 it was to the left. Thus, the position of the P area and master room was reversed in the two houses, which led to two prominent places in the structures being distant from the rear entrance (Fig. 9).

There were also houses in Shuili Town (Libo County) and Shuifu Village (Libo County) with type-B floor plans. All type-B houses were built no earlier than the 1960s. Thus, the type-B kind of main front entrance should be considered a practice that became popular relatively late, and it only appears in southern parts of Libo County inhabited by the Shui.

Owing to the two entrances with type B, the layout space had a centripetal structure around the living room; all the open living rooms with type $\mathrm{B}$ also displayed a centripetal structure. The ancestral altar was located in the centre, and the reception and working areas were separated on either side. Further, the hearth was moved to a secondary position behind the living room: it was no longer juxtaposed with the ancestral altar as with type A. An important feature with type B was the main entrance steps. Some entrances were in the shape of an inverted T-shaped porch, and the entrance faced the ancestral altar (Fig. 10).

In addition to the two typical A and B types, there were some transitional forms. One example was House

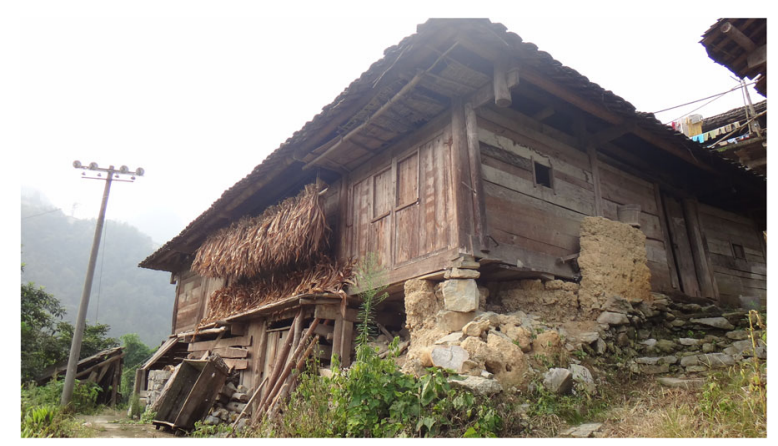

Fig. 8 Appearance of type-A house in Shuifu Village (Source: the authors) 
A (S4) in Bamao Village, Sandu County. According to the householders, Mr. and Mrs. Meng, the building was constructed in around the 1890s. The Mengs and their four children were living there. The house had five bays, and the right bay furthest from the entrance was a recent addition. The main floor had an open living room with two bays in the centre and bedrooms on either side. Above the bedrooms, there were lofts, which were normally used as a children's room or for storage. There was a $\mathrm{T}$-shaped porch in front of the open living room.
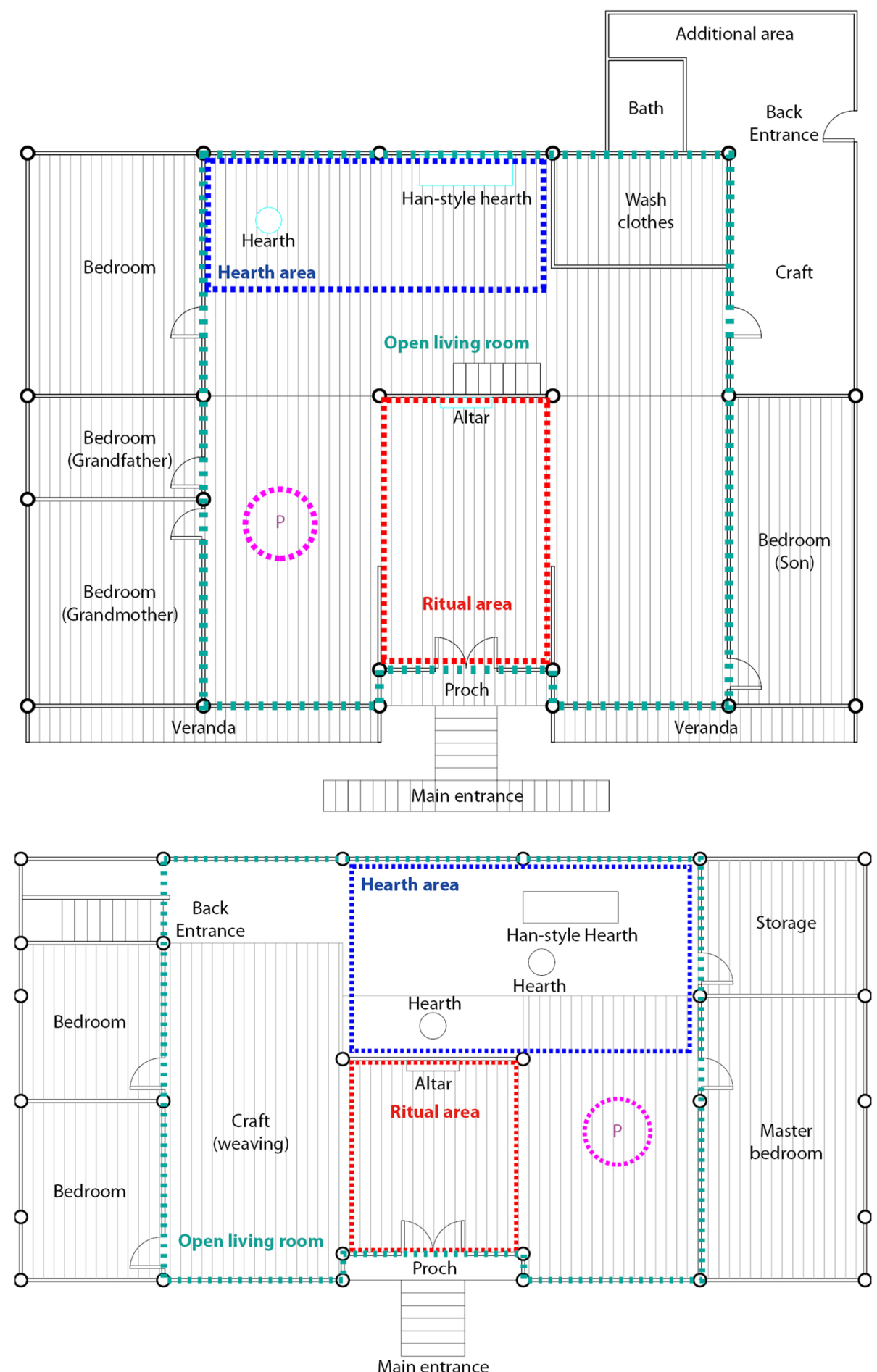

Fig. 9 Floor plans for S7 (upper) and S8 (lower) show the typical type-B layout: two entrances and the open living room being divided into four areas (Source: Yang 2018) 
Of the several bedrooms with S4, only the two rooms on the left side furthest from the main entrance were in use. The bedroom in front nearest the veranda was the master bedroom; the bedroom at the rear furthest from the veranda was for the children. Other rooms were vacant or used for storage; the additional bedroom was also vacant. The two-bay open living room was divided into four quadrants: the main entrance located at the front-left quadrant; the hearth at the front-right quadrant, the ritual area at the rear-left quadrant, and $\mathrm{P}$ area at the front-left quadrant just in the front of the master bedroom and was the furthest point from the main entrance (Fig. 11).

House B (S5) in Bamao Village, Sandu County is another case of a transitional form. Mrs. Meng, the only dweller in S5, said that it was built around 1950. Meng's grandchildren usually came from their new house and spent the daytime there. From the outside, S5 looked symmetrical, but the inner space was asymmetrical. S5 was a three-bay house with the open living room occupying the two left bays. The right bay farthest from the main entrance had two bedrooms. Meng's bedroom was located in the right bay on the rear-right side farthest from the veranda. The room close to the veranda with good light was her living space, and the hearth was moved to that room. The original location of the hearth in the left bay had become a storage area. The P area, where Meng met the authors, was in front of her living space (Fig. 12).

Mo's house (S6) in Hongni Village, Dushan County was also a transitional form. Mo said that his grandfather built the house in around 1900 . When we visited the house in 2013, such wooden houses were seldom used; nearby were new brick houses. Mo's family ancestral altars were still in the house. His family had built a new house nearby, and so the interior arrangements for the old house were modified. The new house featured a new entrance. In the old house, the ritual area was separated by a simple slab in the center of the building, which suggests that it formerly had a three-bay open living room (Fig. 13).

With the transitional form, there is no typical spatial sequence. The spatial characteristics are intermediate between types A and B. S4 was closer to type A, though it was not completely symmetrical; there was an obvious central axis between the concave living room and ancestral altar. S6 was very close to type B: it had an altar in the centre, but there was no entrance stairway on the front. S5 was interesting because it had the tree structure of type A; however, it also had the central axial symmetry of type B and was thus intermediate between the two types.

\section{Ritual and living axes}

Types A and B represent two spatial sequences in Shui houses and reflect two different spatial hierarchy systems. Through spatial syntax analysis, it is possible to further identify two types of axes that correspond to the spatial sequences.

From the spatial sequences described above, it is evident that with both types A and B there are separate spaces for ritual activities and secular daily life. Independent spatial sequences serve the two different functions. With ritual activities, the Shui believe that in a ceremony when making offerings to ancestors, the souls of the ancestors enter the open living room from the windows (type A) or door (type B) via the veranda and go to the altar. Thus, the main entrance, veranda, open living room, and altar constitute a spatial sequence, with the altar holding the highest rank. For secular daily life, the family members enter the workspace of the open living room through the entrance (with type $B$, this is the rear secondary entrance); they then reach the hearth area and finally enter the master bedroom via the $\mathrm{P}$ area. With this sequence, the hierarchy of the spatial elements is also from low to high, the master bedroom having the highest rank.

Thus, we identified two spatial axes in the Shui houses: the ritual axis and living axis. Visibility graph analysis using depthmapX indicated that the visual centre of Shui houses was usually the door of the master bedroom (Fig. 14), which supports the existence of the living axis. When we added the room's furniture and hearth to the floor plan for further analysis (because they affect the visual penetration), the living axis from the entrance to the master bedroom clearly emerged. In addition, two important nodes became evident: one was in front of the master bedroom ( $\mathrm{P}$ area); the other was the worship space in front of the ancestral altar. That oblique axis divided the open living room into four areas. The main entrance and entrance to the master bedroom were located on one of the diagonals; the hearth and ancestral

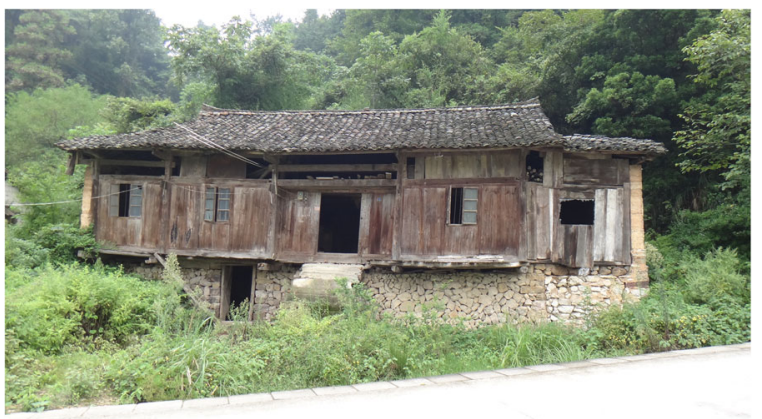

Fig. 10 Appearance of type-B house in Shuili Village (Source: the authors) 
altar were on the other diagonal. The locations of the hearth and ancestral altar were static, whereas the location of the two entrances was dynamic. With this oblique movement of people in the house, it became clear that the more inward-facing the space, the spiritually higher was it considered. In several cases, the master bedroom was located diagonally opposite the entrance, i.e., it was the innermost room and demanded the longest route to reach. The children's room, working spaces, and storage rooms were located next to the entrance stairway. Thus, the spatial arrangement in Shui houses follows a kind of logic from outside to inside.

The different locations of the ancestral altar had a great influence on the spatial arrangement. When the hearth and ancestral altar were located in opposite diagonal areas, the ritual and living axes almost coincided. This may be a remnant of a more ancient floor plan; it points to ancient central-pillar worship among ethnic minorities in Southwest China.
When the ancestral altar is located at the centre of the house, its symmetry is reinforced and the ritual axis becomes dominant over the living axis. However, space visibility analysis indicates the presence of an oblique living axis from the main entrance to the master bedroom. The difference is that the ancestral altar was located in a central area with type B, and that was also the centre of the whole building. Thus, the open living room was divided into two parts by the altar: a living space at the front and a storage space at the rear. With type $\mathrm{B}$, the fundamental difference from type $\mathrm{A}$ is that the location of the hearth is no longer fixed: it is located behind the ancestor altar. As a result with type $\mathrm{B}$, the hearth and ritual area were not equally important owing to the higher status of the ancestral altar. With type B, the living space in front of the altar was further divided into three parts: the worship area was located in the centre, and the spaces on either side were used for daily life and visitors. The $\mathrm{P}$ area for receiving visitors
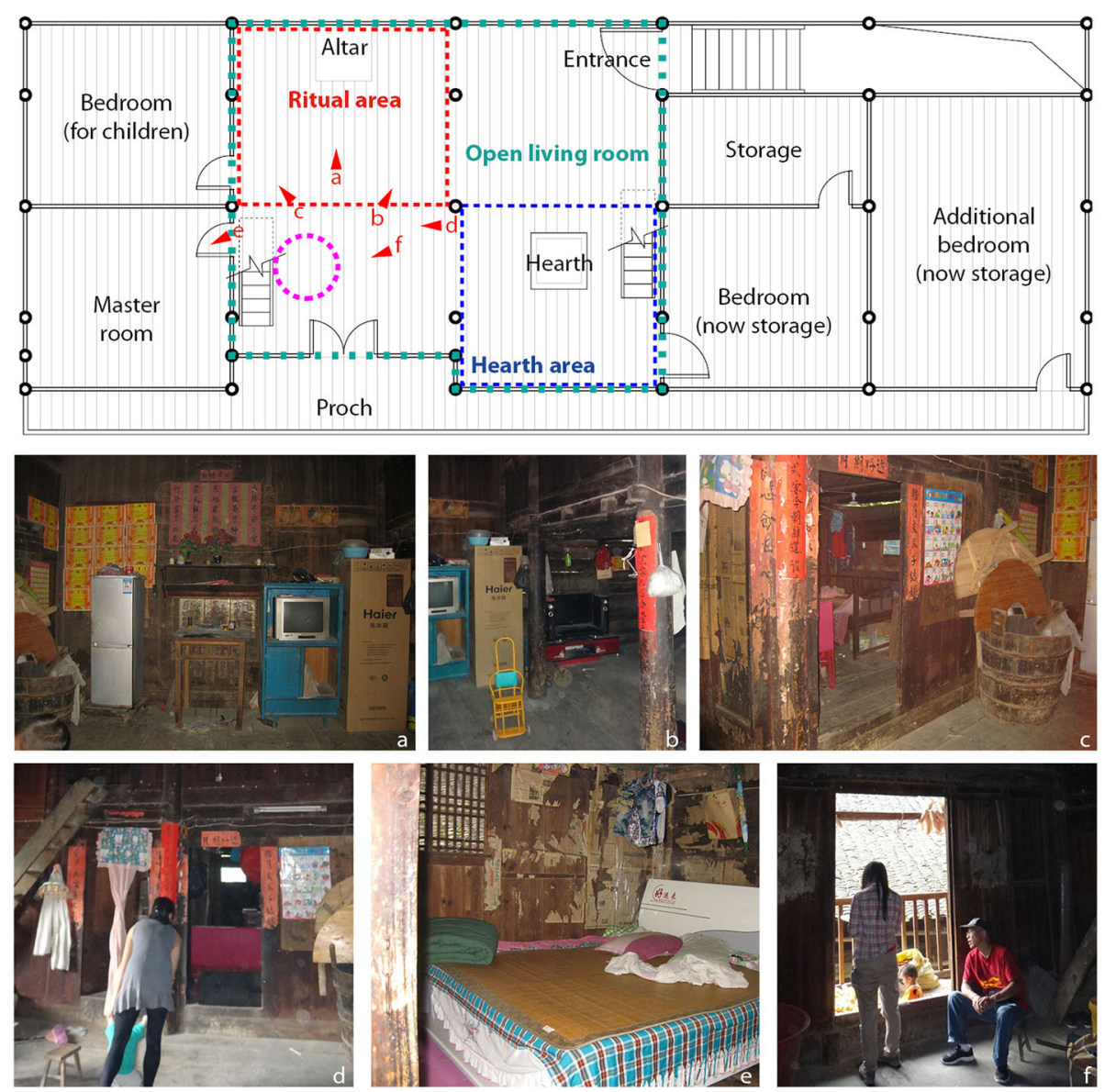

Fig. 11 Floor plan and photos of S4 show that its layout was similar to type A: it had a front (entrance, photo b), middle (ritual area, photo a), and rear ( $P$ area, photo $d$ and master bedroom, photo e). It also had a T-shaped porch (photo f), which is similar to type B to emphasise the orientation of the altar and ritual area (photo a) (Source: the authors) 
with type B was still located in front of the master bedroom.

\section{Sinicisation and ethnicity: characteristics of living space and cultural exchange}

Regarding the visibility of types A and B, we may speculate that type A (with a front-middle-back spatial sequence) belongs to the distinctive Shui tradition. It has a linear spatial series: the higher the status of the space, the closer it is to the end of the visual axis. By contrast, type B (with a left-middle-right spatial sequence) appears to belong to the Han tradition. It has a symmetrical floor layout with the ancestral area along the central axis: the higher the spatial status, the closer is the space to the central axis. The combination of the two axes shapes the multifunctional use of the open living room, which is the key feature of Shui houses. Type A is a distinctive Shui plan and differs from the layouts found with other ethnic minorities in Guizhou; type B is very close to the plan of traditional Han houses.

The coexistence of type A, type B, and various transitional types implies that the Shui house form has been constantly influenced by foreign cultures. Since the Ming
Dynasty (1368-1644), China's central government has made efforts to reclaim the ethnic minorities in the southwest of the country. Ancestor worship, which is central to Han culture, started to influence indigenous cultures. Owing to the growing development of transportation and a centralised political system, that process of Sinicisation became increasingly apparent in the twentieth century. It is evident in the appearance of the type-B plan in the early twentieth century and disappearance of type A in the 1950s. Further, the ritual axis became progressively dominant, while the living axis has gradually weakened. That is manifested in the various transitional forms in the first half of the twentieth century.

With respect to when the houses were built, type A is likely the inherent Shui living mode, whereas type B is the result of Sinicisation. Houses built before 1900 belonged mainly to type A (S1-S3). Columns divided the open living room into four areas, i.e., the main entrance, $\mathrm{P}$ area, hearth area, and ritual area. The hearth and ritual areas were located diagonally or at opposite corners. The connecting line between the main entrance and master bedroom entrance passed obliquely through
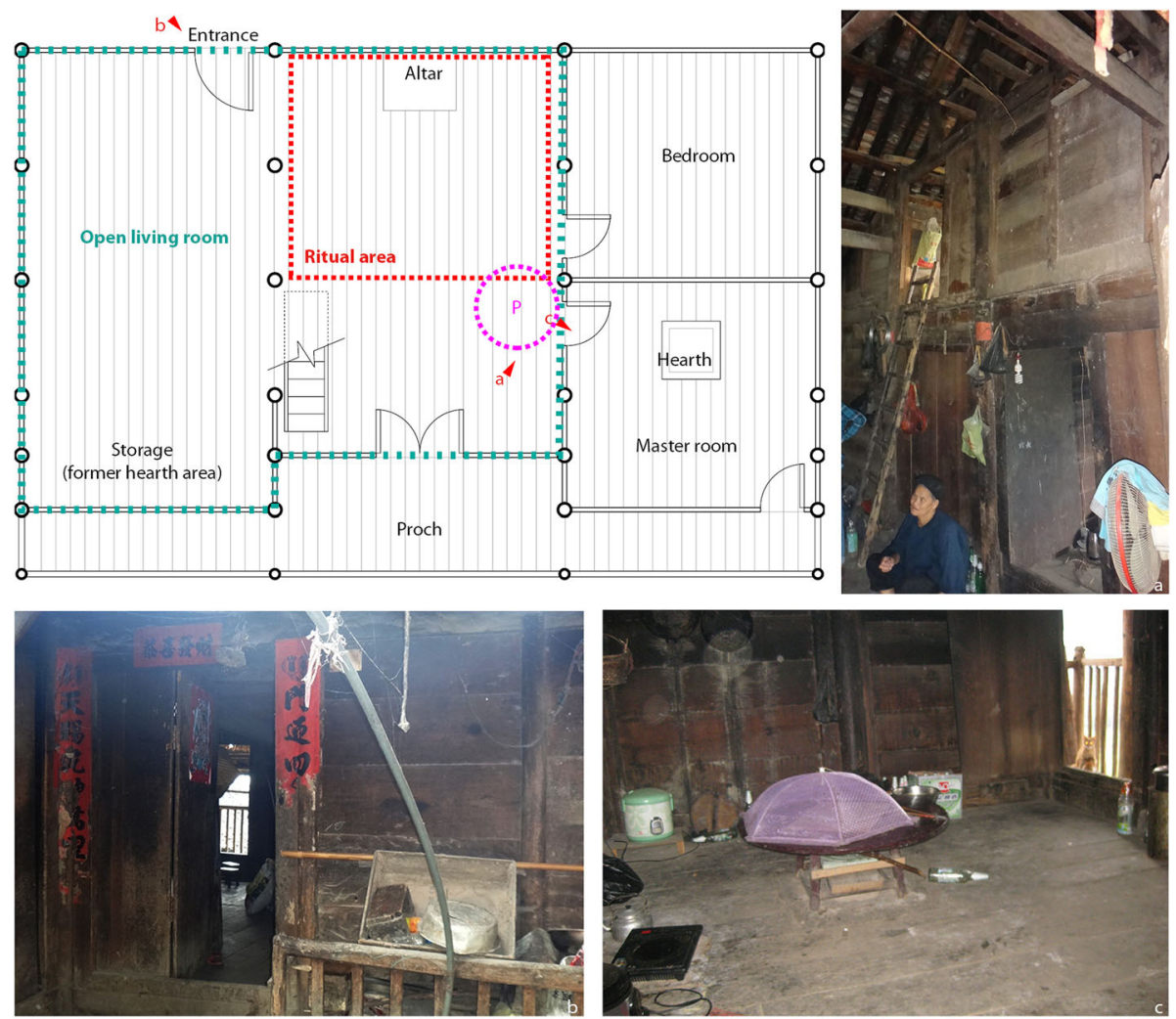

Fig. 12 The floor plan and photos of S5 show a sequence from the entrance (photo b) via the P area (photo a) to the master bedroom (photo c), which is similar to type A. The symmetrical axis from the T-shaped porch to the altar is similar to type B (Source: the authors) 

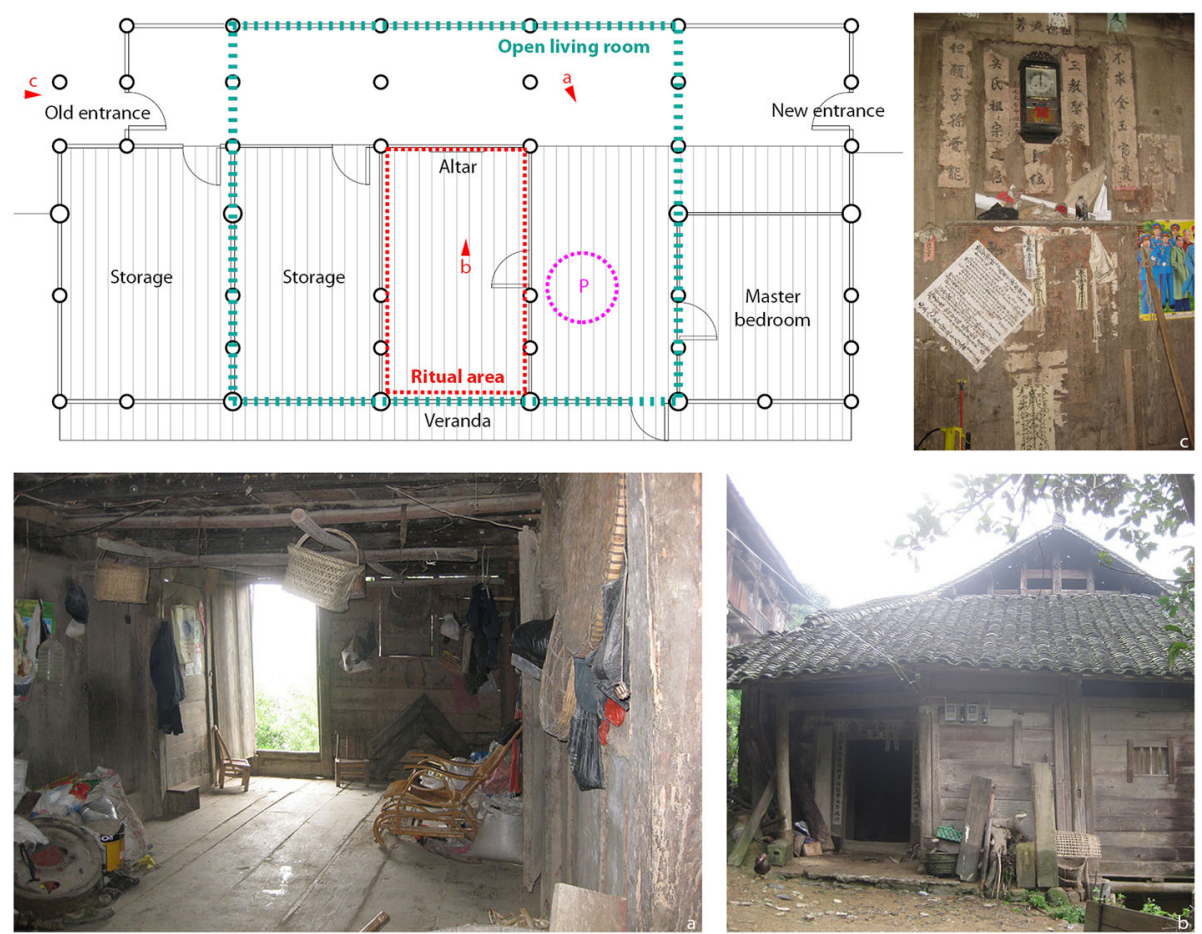

Fig. 13 The floor plan and photos of $\mathrm{S} 6$ show the $\mathrm{P}$ area (photo a) and rear entrance (photo b), which are similar to type A. The ritual area (photo c) and open living room divided into four parts are similar to type B (Source: the authors)

the open living room to form a living sequence; that left the hearth and altar on different sides of the living sequence.

Most houses built after the 1950s were of type B. The main entrance was moved to the front centre, directly facing the ancestral altar. Such spatial organisation is a complete adoption of Han customs. We found cases similar to S8 in the intermediate state: the open living room was divided into front (living space) and rear areas (working space with hearth). The position of the hearth was relatively flexible. The living space could be further divided into three areas: the worship area in the centre and spaces on either side used for daily life and receiving visitors.

Houses built between 1900 and the 1950s mainly present a transitional character. Built in the late 19th century, S4 was similar to type A. S4 had a concave open living room facing the altar, which strongly implied the ritual axis. Built in the 1950s, S5 was a three-bay building with the ancestral altar in the center. S5 was axially symmetrical, but the main entrance was located at one corner. Built around 1900, S6 had an altar quite similar to type B. However, S6 lacked an entrance at the front, which made its ritual axis weaker than the living axis (Figs. 14 and 15).

Some Shui houses built after 1900 and most Shui houses built after the 1950s had an added middle gate, which is similar to traditional Han dwellings; the main entrance was moved to the front of the building. We observed that in such cases, the spatial organization changed completely into one of axial symmetry. Further, the oblique living room axis had disappeared.

The changes in the layout reflect the influence of Sinicisation on ethnic minority residences in Southwest China in the twentieth century. The traditional living Shui space focused on the living axis: it developed around the route from the main entrance to the master bedroom, which held the highest status (followed by the hearth). As an element of foreign culture, the ancestral altar was not included in the living axis. Gradually, the Shui living space developed into a pattern highly consistent with Han lifestyles, and it featured a central ritual axis. This process of Sinicisation may have continued for centuries, but we were able to verify it only over the past 100 years.

\section{Conclusions}

Shui vernacular houses are typical minority dwellings that underwent constant cultural change: under the influence of Han culture, their spatial layout gradually changed from type A to type B. First, the open living room was used to organise the public area of the house. The connection between the open living room and the entrance, balcony, and bedrooms shaped the two types of plan layout. Second, the different locations of the hearth and ancestral altar in the open living room 


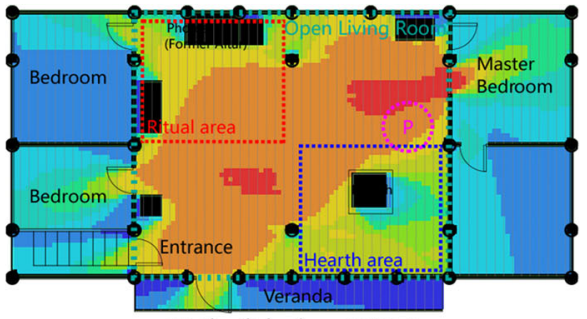

S1 (built before 1900s)

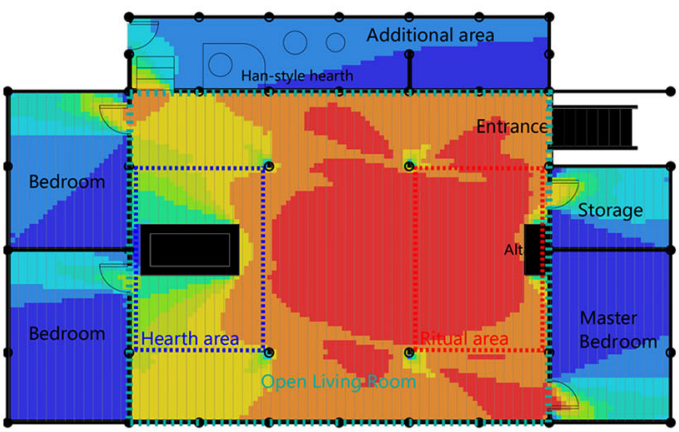

S3 (building date unknown)

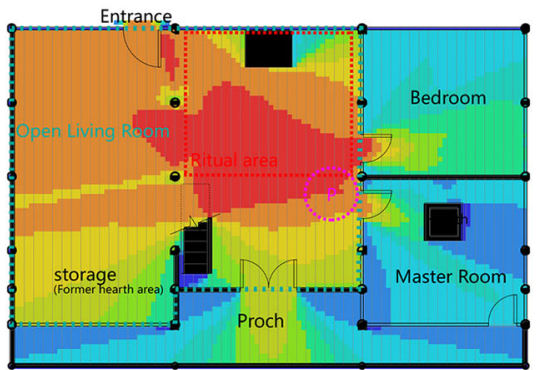

S5 (built in 1950s)

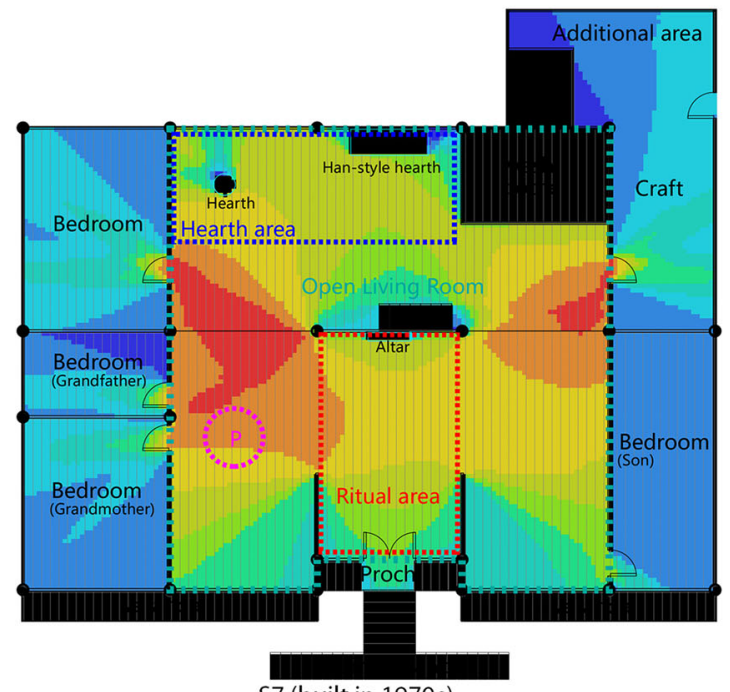

S7 (built in 1970s)

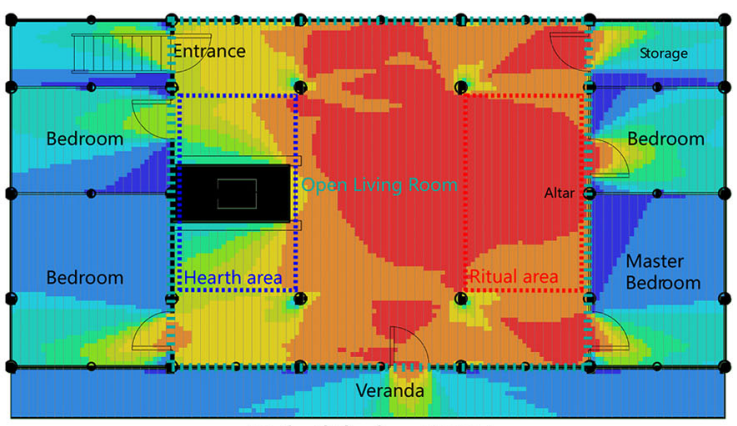

S2 (built before 1900s)

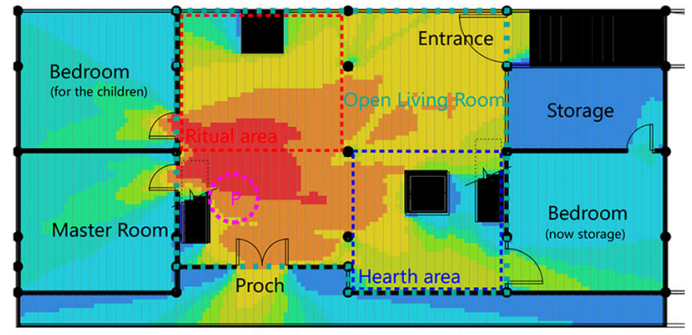

S4 (built before 1900s)

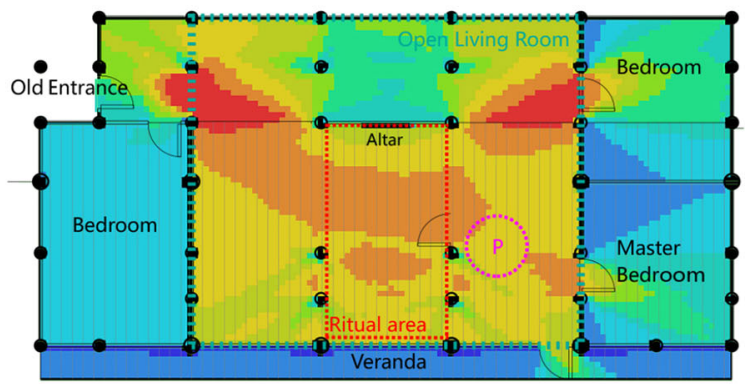

S6 (built around 1900)

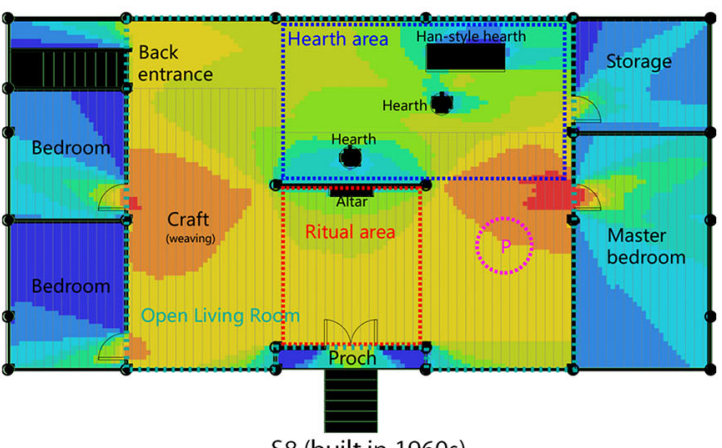

S8 (built in 1960s)

Fig. 14 depthmapX uses a geometric algorithm to analyse the visibility of each grid point in space. The red area shows high visibility (strong connection with other areas); the blue area shows low visibility. Generally, the redder the space, the higher is the probability various activities will occur there. It is evident that the P area has a significant connection with the red area. Moreover, the red area has obvious directionality, which indicates the possibility of an axis (Source: the authors) 


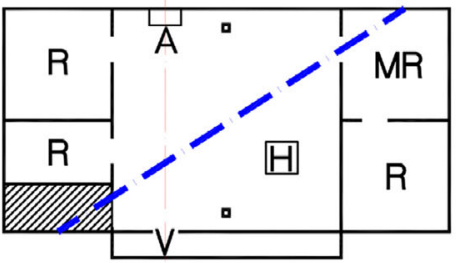

S1

Type A before 1900

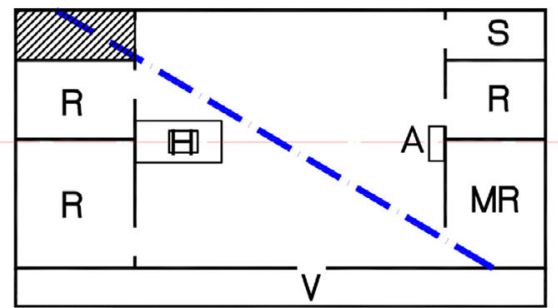

S2 (by Luo, D. 2016)

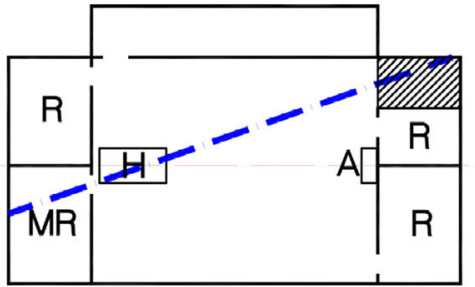

S3 (by Lu, Y. 2004)

Transitional Form 1900-1950

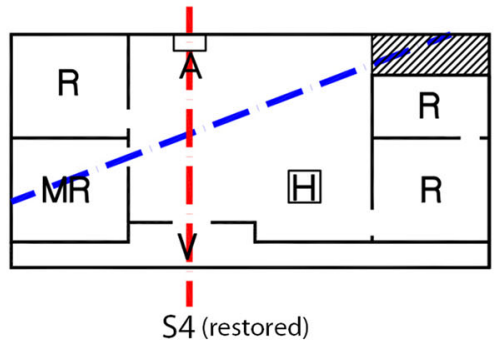

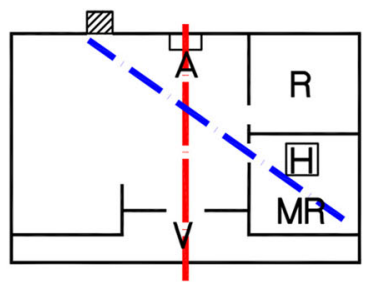

S5

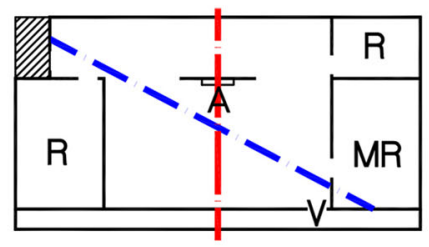

S6 (restored)

Type B After 1950

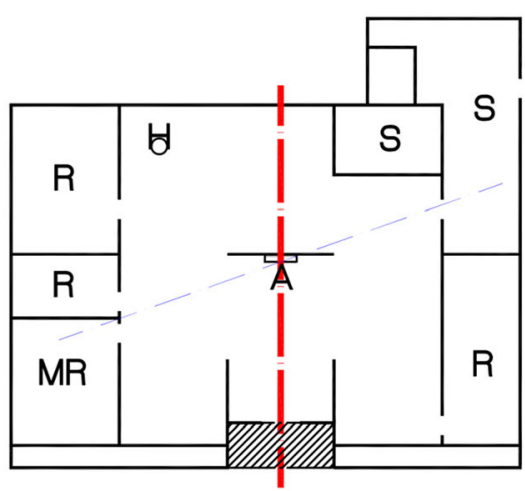

S7 (by Yang, T. 2018)

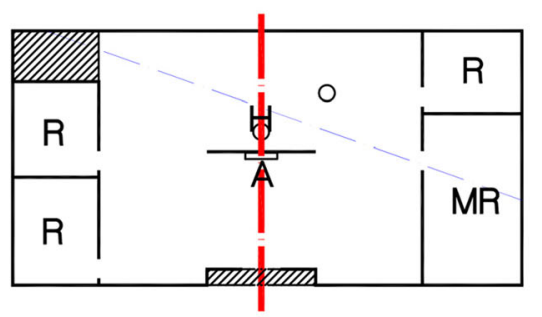

S8 (by Yang, T. 2018)

Fig. 15 Ritual and living axes are quite different between types A and B (Source: the authors)

affected the spatial layout. Through visual analysis with space syntax, we identified two axes of ritual and daily life. The level of cultural exchange was reflected in changes to the two axes. The tendency to emphasise the ritual axis was the dynamic force in the change from type A to type B.

It should be noted, however, that the two types of plan seen in the layout of Shui houses are widely evident in other minority houses in Southwest China as well as other parts of East Asia. For example, two kinds of spatial patterns are seen in Dong vernacular houses in Guizhou Province: the front-middle-back pattern (like type A in Shui houses) has the sequence of entrance, wide veranda, living room, fire pit room, and bedroom; the left-middle-right pattern (like type B in Shui houses) is centered on the ritual area (Ruan 2006; Asakawa 1994). Dai dwellings in Yunnan Province are similar to those of the Dong: both left-middleright and front-middle-back layouts exist (Shen and Yang 2014). More primitive Mosuo houses in Yunnan Province mainly have a front-middle-back layout and a main living room (Asakawa 1994). The spatial pattern of minka dwellings in Japan is also a front-middle-back model of entrance and earthen-floor room (used as kitchen and workplace) in the front and a living room at that rear (Ooda et al. 1999); that is similar to the combination model of minority residential buildings in Southwest China.

In contrast to the front-middle-back layout seen in Yunnan and Guizhou provinces, and Japanese dwellings and the left-middle-right layout in traditional Han dwellings, the layout with two axes seen in Shui houses 
reflects a possible cultural exchange in the wider geographic context of East Asia. However, the specific routes and manner in which the cultural exchange occurred with the in minorities in Southwest China area are still unclear. The indigenous culture of Shui houses is pluralistic and diverse. It is necessary to comprehensively study the traditional cultural heritage in ethnic minority areas to avoid labelisation and oversimplification as a kind of 'ethnic style' for tourist purposes and also to protect cultural diversity.

\section{Acknowledgements}

We thank Stephen Forster from Liwen Bianji, Edanz Editing China (www. liwenbianji.cn/ac), and Yingchun Li for editing the English text of a draft of this manuscript.

\section{Authors' contributions}

Yizhi Zhou conceived the idea and conducted the analyses; Miao Wei provided the data; all authors contributed to the writing and revisions. The author(s) read and approved the final manuscript.

\section{Funding}

This paper is supported by the National Natural Science Foundation of China (No. 51738008, 51678415).

\section{Availability of data and materials \\ Not applicable.}

\section{Competing interests}

Not applicable.

\section{Author details}

${ }^{1}$ College of Architecture and Urban Planning, Tongji University, 1239 Siping Road, Yangpu District, Shanghai 200092, China. ${ }^{2} \mathrm{H}+$ Architecture and Engineering Co., Ltd, 1728-2 Huangxing Road, Yangpu District, Shanghai 200433, China.

Received: 21 February 2020 Accepted: 20 December 2020

Published online: 19 February 2021

\section{References}

Alitajer, S., and G.M. Nojoumi. 2016. Privacy at home: Analysis of behavioral patterns in the spatial configuration of traditional and modern houses in the city of Hamedan based on the notion of space syntax. Frontier of Architectural Research 5: 341-352.

Asakawa, Sinan. 1994. Sumai no minzoku kenchiku-gaku [Ethnic architecture of residence]. Tokyo: Kenchiku Shiryo Kenkyusha.

Bao, Muping. 2015. Jianzhu wenhua chuanbo yu jiaoliu de yanjiu xianzhuang yu keti-yi zhongguo shaoshu minzu diqu weili [Research status and issues of architectural culture dissemination and exchange-Taking Chinese minority areas as an example]. Journal of Chinese Architecture History 2: 49-62.

Choi, Jaepil, Kim Youngwoo, and Junekyung Kang. 2014. Comparative analysis of the spatial structure of apartment unit plans in Asia-Apartments in Korea, Vietnam, and Kazakhstan. Journal of Asian Architecture and Building Engineering 13 (3): 563-569.

Huang, Bo-Xun, Shang-Chia Chiou, and Wen-Ying Li. 2019. Study on courtyard residence and cultural sustainability: Reading Chinese traditional Siheyuan through space syntax. Sustainability 11 (6): 1582

Long, Hualou, and Yansui Liu. 2016. Rural restructuring in China. Journal of Rural Studies 47: 387-391.

Lu, Yuanding. 2004. Zhongguo minju jianzhu [Chinese vernacular architecture]. Guangzhou: South China University of Technology Press.

Luo, Deqi, and Duofu Li. 2016. Guizhou gujianzhu [Guizhou ancient architecture]. Beijing: China Architecture \& Building Press

Ooda, Hirotarou, Keisuke Fujii, Nagajirou Miyamoto, Katsuhisa Ueno, Shigeru Maruyama, Teruaki Maruzaki, Ikuo Hirayama, et al. 1999. Nihonkenchiku yōshiki-shi [The concise history of Japanese architecture]. Tokyo: Bijutsu Shuppan-Sha.
Ostwald, Michael J., and Michael Dawes. 2013. Differentiating between line and point maps using spatial experience: Considering Richard Neutra's Lovell House. Nexus Network Journal 15 (1): 63-81.

Ruan, Xing. 2006. Allegorical architecture: Living myth and architectonics in southern China. Hawaii: University of Hawaii Press.

Shen, Jichao, and Dayu Yang. 2014. Leixingxue shiye xia de Yunnan daizu chuantong minju kongjian goucheng fenxi [Analysis of the Dai traditional dwelling space in Yunnan from the perspective of typology]. Huazhong Architecture 5: 165-168

Wang, Shaozhou. 1998. Zhongguo minzu jianzhu [Chinese vernacular architecture]. Vol. 1. Nanjing: Jiangsu Science and Technology Press.

Wei, Chengjian. 2009. Guizhou sandu shuizu ganlanshi minju jiqi jianzhu wenhua de sikao [Sandu County's railing-enclosed house and their architectural culture]. Journal of Guizhou University for Ethnic Minorities-Philosophy and Social Science 4: 73-75.

Wu, Zongjie. 2014. Let fragments speak for themselves: Vernacular heritage, emptiness and Confucian discourse of narrating the past. International Journal of Heritage Studies 20 (7-8): 851-865.

Xu, Ying, Bo-sin Tang, and Edwin H.W. Chan. 2011. State-led land requisition and transformation of rural villages in transitional China. Habitat International 35 (1): 57-65.

Yang, Tongshu. 2018. Shuizu chuantong cunzhai yu minju jianzhu xingzhi jiegou-yi Guizhousheng Liboxian Shuipazu weili [The traditional villages of Shui minority and the shape and structure of residential buildings: A case study of Shuipa village, Libo county, Guizhou province]. World of Antiquity 1: 60-64 31.

Zhang, T.X., T. Yamamura, and Y. Fujiki. 2006. Can vernacular buildings survive with traditional life inside and tourism outside? In Sustainable tourism II: WIT transactions on ecology and the environment, ed. C.A. Brebbia and F.D. Pineda, 171-180. Southampton: WIT Press.

\section{Publisher's Note}

Springer Nature remains neutral with regard to jurisdictional claims in published maps and institutional affiliations.

\section{Submit your manuscript to a SpringerOpen ${ }^{\circ}$ journal and benefit from:}

- Convenient online submission

- Rigorous peer review

- Open access: articles freely available online

High visibility within the field

Retaining the copyright to your article

Submit your next manuscript at $>$ springeropen.com 